adapt themselves to available diet, low in calories and low in protein but with protein value about adequate for health, and who eventually cstablish some sort of equilibrium between body-weight, development and physical activity on the one hand and low intake of food on the other, the need is for more food of the type they are eating today.

That diets based on cereals and pulses commonly taken in India have a protein value adequate to cover protein needs of man at all ages has been shown by a number of workers (Payne, 1969; Aykroyd \& Doughty, 1964). The exceptions are pregnant and lactating women who require a slightly higher concentration of utilizable protein than is present in the diet based on rice and pulses, though even here small supplements of milk can more than adequately cover needs. Infants are also exceptions since they cannot be given solid diet if they are weaned during the Ist year. Protein-rich foods of high biological value, such as milk and eggs, which along with better-quality protein also bring minerals and vitamins, have clearly a vital part to play. Further discussion is beyond the scope of this paper.

I am grateful to Dr C. Gopalan for reading parts of the draft and for his comments. I am also grateful to my colleagues in the Statistics Division for their help in the calculations done for the paper.

\title{
REFERENCES
}

Aykroyd, W. R. \& Doughty, J. (1964), F.A.O. nutr. Stud. no. I9.

Calloway, D. H. \& Spector, FI. (1954). Am. F. clin. Nutr. 2, 405.

FAO (1957). F.A.O. nutr. Stud. no. 15.

FAO (1965). F.A.O. Nutr. Mtg Rep. Ser. no. 37.

Gopalan, C. (1968). In Calorie Deficiencies and Protein Deficiencies [R. A. McCance and F. M. Widdowson cditors]. London: J, H. Churchill Ltd.

Gopalan, C. (1969). Int. Congr. Nutr. viri, Prague. (In the Press.)

Indian Council of Medical Research (1968). Recommended Dietary Allowances for Indians. Delhi: Indian Council of Medical Research.

Miller, D. S. \& Paync, P. R. (1961). F. Nutr. 75, 225.

Payne, P. R. (1969). Voeding 30, 182.

Sukhatme, P. V. (1961). Il R. statist. Soc. 124, 463 .

Sukhatme, P. V. (1969). Proc. Nutr. Soc., India no. 8 , p. т.

Sukhatme, P. V. (1970). Br. Y. Nutr. 24, 477 .

Telang, M. A., Vidwans, S. M. \& Puntambckar, V. J. (1962). Q. Bull. Econ. and Statist., JulySeptember, Bureau of Economics and Statistics, Government of Maharashtra.

WHO (1965). Tech. Rep. Ser. Wld Fllth Org. no. $30 \mathrm{I}$.

\section{Factors affecting the nutritional status of urban communities}

By R. U. QuREshI, Glaxo Research Limited, Greenford, Middlesex

\section{Introduction}

Before embarking on the factors affecting the nutritional status of urban communities in developing and developed countries, it is important to examine briefly the status of their agriculture. 
In most economically and technologically developed countries agriculture is efficient and food can be readily produced often in excess of the countries' needs. Manufacturing industries are also highly developed so that food is plentiful, whether from home production or imports. Food processing and conservation methods are sophisticated and commonly used to prevent losses in stores, to improve quality, to conserve nutrients and to maintain consistent supplies of otherwise perishable commodities throughout the year.

In many developing countries, agriculture during the last two decades has progressed faster than ever before. Through international co-operation it has been made possible to bring more land under the plough, and enormous resources have been employed to increase crop yields. Government investments in fertilizer factories and irrigation systems, for instance, have been substantial. Agricultural productivity in many of these areas has increased, but so has the need for consumer goods. Expensive consumer goods are imported from industrialized countries in exchange for the cash crops and minerals which may be exported. The land and resources thus used for cash crops are not available for food production so that often the increasing production of human foods has barely kept pace with the needs of the enlarging population.

\section{Urban communities in developed countries}

Food is often produced at a considerable distance from cities. Some degree of preservation is necessary to transport food from rural to urban areas, but in developed countries excellent transport systems and modern food processing industries permit ready availability of both perishable and preserved foods in the cities as well as in the rural areas. Because of the time needed to work, to obtain money or because of the many attractions offered to fill leisure hours, many people do not plan their meals, cook properly and sit down to eat patiently. It is more convenient for them to grab and bolt something palatable that requires the least amount of cooking, or better still, no cooking at all! Because of the wide variety of foods available and because of the desire for varied meals, the risk of nutritional deficiencies is not great, as long as people have money to buy the things they wish to eat. Although nutrient deficiencies can, and do, exist in developed urban communities, they are found only amongst the deprived, ignorant or eccentric. Much more common are the problems of obesity and dental decay resulting from over-indulgence in some of the more palatable food items.

Food processing carried out scrupulously can avert some of the dangers of wrong feeding by conserving the nutrients of preserved and processed foods and by the preparation of properly balanced nutritious meals. Ready-to-eat meals can be made available at all times, not only at the family level, but also at the community level to be consumed at home, at work, or in public restaurants.

\section{Effects of processing on foodstuffs}

Processing of foodstuffs is undertaken to improve palatability and to increase the shelf life of cooked and uncooked foods. The principal operations of processing 
include drying, freezing, chilling, sterilization, canning and addition of preservatives which may be employed singly or combined. Processing of foodstuffs can improve the supply of nutrients from some and adversely affect it in others. The structure of food, its flavour and taste also undergo modifications. Brevity prevents discussion of all the changes brought about by various processing techniques, but a few important ones will be described.

Drying and heat treatment. Drying of foodstuffs can be achieved by the evaporation of water at high or low temperatures and from the frozen food. The latter process is called freeze-drying, and it brings about the least possible change in flavour or nutritional qualities. In fact fresh varieties of foods are likely to lose more nutrients by wilting and bruising than by freeze-drying or freezing soon after harvesting. Heat treatment can increase digestibility or rcmove toxicity. Jaffé \& Vega Lette ( 1968 ) showed that some beans of the Phaseolus species (red, white and black beans and mottled beans) and soya bean (Glycine max) which are known to contain either trypsin or amylase inhibitors, or both, lose their toxicity if heated before consumption.

Kodicek, Braude, Kon \& Mitchell (I956) showed that the treatment of maize with lime produced better growth of animals either due to the liberation of bound nicotinic acid or to an increase in the availability of amino acids. Bressani, Castillo \& Guzmán (1962) produced the same effect as lime treatment by heat and pressure. However, heat treatment can lower the biological value of proteins by reducing the availability of sulphur-containing amino acids and lysine. Nevertheless, combination of lysine with reducing sugars in the Maillard reaction though decreasing nutritional value can increase the attractiveness and palatability by modifying the colour, flavour and aroma of cereal food products, meat extract and malt extract.

Thiamine is heat-labile and much is lost during processing, particularly under alkaline conditions. Loss of ascorbic acid resulting from oxidation during processing is very high but according to Bender (I966) steam blanching protects it by inactivation of the enzyme ascorbic acid oxidase. These vitamin losses can be equally high during ordinary home cooking of the fresh food.

Food additives and fortification. Some common foodstuffs are nutritionally improved by fortification. In the United Kingdom wheat flour is fortified to contain not less than $0.24 \mathrm{mg}$ thiamine, $\mathrm{r} \cdot 6 \mathrm{mg}$ nicotinic acid and $\mathrm{r} \cdot 65 \mathrm{mg}$ iron per $100 \mathrm{~g}$. Retinol, ergocalciferol, ascorbic acid and iron are commonly added to milk powder to ensure its nutritional adequacy for the infant. The addition of antioxidants, artificial flavours, sweeteners, emulsifying agents and many other substances is a controversial aspect of food technology. These products are added for various reasons: to prevent deterioration, to improve quality, to facilitate processing and to increase acceptability, for instance. Benefits, lower cost and better taste and appearance, must be weighed against the possible risks which may follow the use of these additives. For instance, the possible toxic effects of an artificial swcetening agent should be weighed against the benefits such as the decrease in obesity and consequent morbidity, the decrease in dental caries in children or the increased variety of diabetic foods which could flow from its use. Approved lists of food additives are 
available in each country for the guidance of the food industry. More research work is necessary to validate further the use of these additives not of food origin.

\section{Consumer choice and influence of food technology}

It is believed that food technology influences food habits and therefore nutritional status. Commercially it is never sensible to produce anything if there is no demand. There would be no convenience food if city dwellers did not eat it. Also, it is well known that technological skill alone is not a justification for marketing a food product. For example, the food of an astronaut in flight is technologically sophisticated and nutritionally elegant, but its marketing for the general public now would be an economic failure. As in all other species, the evolutionary survival of man depended on proper food choice. He rejected the foods that made him ill and selected the ones that kept him alive and recognized them through the senses, sight, taste, smell, touch and hearing. The appearance, odour, texture and taste of the food to which he is accustomed are therefore extremely important factors in determining choice of food. Long ago, the gastronomist convinced the food manufacturer that he must base his products on organoleptic tests. Today food appeals to the eye and is delicious to eat, but attractive foods are not necessarily adequate nutritionally. Nutritional awareness is comparatively new. Extensive efforts have been made to disseminate nutritional knowledge among the masses, yet whenever an evaluation is published, one is dismayed to discover that even in urban communities the impact has been slight. The combination of mass media and pseudo-nutrition is hampering the honest efforts of the nutritionist. Compared with the consumer the food manufacturer is more receptive to sound nutritional advice and only too willing to bring his products up to date. The nutritionist must take this opportunity and it is reasonable to assume that the food industry will meet his expectations.

\section{The state of nutrition}

In general the nutritional status of urban communities in developed countries is good. Growth curves of London schoolchildren and growth charts of Boston infants are used as reference standards all over the world. However, malnutrition through wrong feeding is encountered in certain sections of these communities.

Elderly people, through economic pressures or living in isolation, may suffer from undernutrition and vitamin deficiency diseases. Obesity is present in all age groups. The precise biochemical mechanism of obesity is not understood, but it is generally agreed that obesity is a consequence of overeating and sedentary habits. Billy Bunters begin in the cradle. Young mothers who worry unnecessarily about the slow weight gain of their babies often make them fat through overfeeding and even force-feeding. Some parents encourage their children to eat enormous meals throughout childhood. Once established these food habits persist and so the accompanying obesity is the more difficult to control. Nutritional problems of schoolchildren are different. Lynch (1969) found that between a quarter and a third of the schoolchildren in his survey went without breakfast. Also many children refuse to drink milk and dislike school meals. Instead of eating nutritious and inexpensive food, 
schoolchildren consume sweets, chocolates and soft drinks, and so may become malnourished and develop bad teeth. Nutritional problems of affluence are as intricate as those of the underprivileged, and, being sociological in origin, are more difficult to solve.

\section{Urban communities in developing countries}

Urbanization is a dynamic development resulting from economic, cultural and social changes in rural communities. The successful growth of urbanized sectors depends on the wealth of resources around them. These resources include the supply of raw materials and labour for the development of industry. The young people, who are motivated to leave the villages and rural work by the higher wages in industry are usually unskilled and have little or no experience in managing their own affairs. The marked independence of life in urban communities contrasts with the strong communal life in rural areas. In villages people usually live in a joint family system, pooling their food and money to ensure fair distribution, within the kinship group, by contrast with the small independent family units who are characteristic of urbanized societies.

In urban communities, essential requirements such as water supply, education, sanitation, housing and transport may be greatly improved. The practice of preventive and therapeutic medicine can reduce epidemics, and incidence of disease. This is, however, only possible if the development of these services can keep pace with the growth of the city. Urbanization in developing countries is usually rapid and unplanned, so that it is often difficult for the extension and development of housing and other facilities to keep pace with the increasing demands. Ideally, higher educational attainments in cities should afford expertise for the rural development and both the communities should progress simultaneously.

\section{Income and expenditure}

Cash income per capita is often substantially higher in urban communities than in rural populations, but nutritional standards are often lower. In towns money is used for the necessities of life other than food. The higher income is insufficient for all the essentials of town life, rented accommodation replaces a communal shelter, and money is needed for transport to work and for the clothes temptingly displayed to provide greater satisfaction of personal desire. Primary education may be compulsory but is normally not free. Medical care, although virtually non-existent in villages, is available in towns, but is costly. For these reasons the cash available for food may be reduced while in the towns perishable, protective foods are usually less readily available and there is practically no opportunity for the urban as opposed to the rural dweller to produce his own food. The commonly employed monthly system of wage payment also leads to difficulties in that there is considerable variation from week to week in the food consumption of monthly-paid workers. Perhaps it is not surprising to find that pay day is often the family feast day, and expensive foodstuffs, meat, eggs and milk, are eaten at the beginning of the month, while towards its end the staple food predominates and the number of meals may be 
reduced. Families tend to economize on food and to be extravagant in other things. According to the proverb: no-one need know what you eat, but all can see what you wear.

\section{Food supplies}

Most developing countries are in hot and humid regions, and fresh foods, particularly of animal origin, are more susceptible to deterioration and wastage. Food from rural areas is brought into towns on slow transport. Food technology has developed very little and proper storage and refrigeration facilities are rare. The price of food is affected by lack of preservation, and supply usually lags behind demand. In the circumstances, profit motives have made adulteration of food a common practice.

Fresh milk is collected from villages in pails and pitchers. The containers, often plugged with bundles of grass, are transported to town by foot, bicycle or cart. Lorries are used where roads are suitable, but bacteriological quality can suffer severely during transport, especially during the hot season. At present the industrial production of animal feedstuffs is small in many countries so that meat-producing animals, cattle, sheep and goats, are reared on grazing ground often far from urban centres. The animals may thus trek for days before reaching the market, and on the journey lose considerable weight because other means of transport are uneconomic. Such waste is undesirable in countries where nutritious foods are needed most.

\section{Food habits and nutritional status}

Food habits of urban and rural populations are similar. However, sophistication and socio-economic pressures of town life cause some changes. In towns some infants are fed artificially and are weaned earlier. Aykroyd \& Hossain (1967) made a study of the diet and state of nutrition of infants in Bradford, Yorkshire: they belonged to a Pakistani community and their mothers had recently arrived in England. It was found that in the new environment most of these mothers had given up their traditional method of breast feeding and had successfully adopted artificial feeding in accordance with current British methods. Artificial feeding of infants by mothers in developing countries is less successful because of ignorance and poor hygiene. It is more convenient for the mother but can increase infection and infantile malnutrition. However, under the tutelage of health services this practice can be successful, as found by Aykroyd \& Hossain in Bradford.

In developing countries the nutritional status of higher socio-economic classes is satisfactory. In the rest of the population the classical features of malnutrition and undernutrition, such as low birth weights, higher infant mortality, stunted growth, greater susceptibility to infection and shorter expectancy of life, are as common in urban communities as in rural communities.

In conclusion I would like to emphasize that the entire problem of nutritional status must be analysed in the light of factors responsible for creating it. Therapeutic control of vitamin deficiency diseases, protein-calorie malnutrition and even obesity, is only a temporary measure. Prevention rather than cure must be the 
approach. Nutritionists, food technologists, sociologists, clinicians and administrators should collaborate to control and eradicate malnutrition, whether in urban or rural communities of developed or developing countries of the world.

\section{REFERENCES}

Aykroyd, W. R. \& Hossain, M. A. (1967). Br. med. $\mathcal{F} . \mathrm{i}, 42$.

Bender, A. E. (1966). F. Fd Technol. 1, 26r.

Bressani, R., Castillo, S. V. \& Guzmán M. A. (1962). 7. agric. Fd Chem. ro, 308. Jaffé, W. G. \& Vega Lette, C. T. (1968). F. Nutr. 94, 203.

Kodicek, E., Braude, R., Kon, S. K. \& Mitchell, K. G. (1956). Br. F. Nutr. Io, 5 I.

Lynch, G. W. (1969). Getting the Mast out of Food No. 5, p. 16. London: Van den Berghs Ltd. 